\title{
Monitoring of Excess Body Weight in Children in the Emergency Department of a Tertiary Pediatric Hospital in Bucharest, Romania
}

\author{
Victor Daniel MIRONa, b, Gabriela BARª, Claudiu FILIMON,
} Vlad Alexandru GAIDAMUT ${ }^{b}$, Mihai CRAIUa, b

a"Alessandrescu-Rusescu" National Institute for Mother and Child Health, Bucharest, Romania

b"Carol Davila" University of Medicine and Pharmacy, Bucharest, Romania

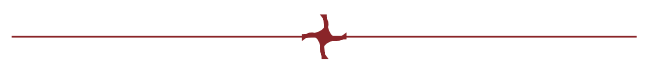

\begin{abstract}
Introduction: Excess body weight in children has become a public health issue in most countries. The aim of our study was to determine the prevalence of overweight and obesity in children over two years of age who presented at the Emergency Department of a tertiary pediatric hospital in Bucharest, Romania.

Methods: Between July and August 2018, we conducted a prospective study among children who presented at the Emergency Department of "Alessandrescu-Rusescu" National Institute for Mother and Child Health, Bucharest, Romania. We collected data on weight, height and blood pressure classified by age and gender.

Results: A total of 335 children aged 2 to 18 years were included in our study. A quarter of them had above normal body mass index values, $7.5 \%$ were overweight and $18.5 \%$ obese. Also, when measuring blood pressure, we observed increased values in $29.3 \%(n=98)$ of them. Among children with excess body weight, nearly a half $(49.4 \%, n=47)$ had higher than normal blood pressure values.

Conclusions: We identified an increased prevalence of obesity in children and adolescents in the last decade. Given that the effects of this condition are not limited to childhood, urgent measures are needed to curb this trend. Both healthcare providers and non-medical members of the society should be involved in promotion of a healthy lifestyle.
\end{abstract}

Keywords: obesity, hypertension, children, emergency department.

\footnotetext{
Address for correspondence:

Victor Daniel Miron, MD, PhD student

"Alessandrescu-Rusescu" National Institute for Mother and Child Health, Bucharest, Romania

Lacul Tei Street, No. 120, Second District, 020395, Bucharest, Romania

Tel: +40749600793

Email: victor.miron@drd.umfcd.ro; mironvictordaniel@gmail.com
}

Article received on the $6^{\text {th }}$ of February 2021 and accepted for publication on the $8^{\text {th }}$ of September 2021 


\section{INTRODUCTION}

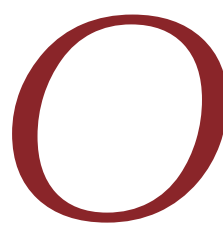
besity in children and adolescents has become a public health problem in most countries around the world in the last decades (1). Recent estimates suggest that approximately $17 \%$ of children between ages of 2 and 19 years are obese (2), and the prevalence of high blood pressure (HBP) for the same age range is now approaching 4\% (3). Body weight and blood pressure (BP) are closely correlated, and studies have shown a directly proportional link between increased HBP prevalence and elevated body mass index (BMI) in children (4).

Childhood overweight is a very common problem in high-income countries, but it has also spread to low and middle-income areas $(5,6)$. A number of factors, including genetic predisposition, socio-economic, psychological, and environmental factors (pollution, lack of green spaces), inadequate nutrition and reduced physical activity contribute to overweight $(7,8)$. Childhood obesity frequently persists into adulthood, with a rate of up to $80 \%$ (9). The same trend was observed for hypertension in children (10).

The aim of our study is to determine the prevalence of obesity a in children over two years of age who presented at the Emergency Department of a tertiary pediatric hospital in Bucharest, Romania.

\section{METHODS}

A e conducted a prospective study to monitor the BMI of children aged 2 to 18 years who presented at the Emergency Department of "Alessandrescu-Rusescu" National Institute for Mother and Child Health (NIMCH), Bucharest, Romania, between July and August 2018. NIMCH is the tertiary children's hospital of the second district of Bucharest and PiperaVoluntari suburban area, with more than 45.000 pediatric outpatients per year. The second district of Bucharest is a metropolitan area of about 70 square $\mathrm{km}$ with a population of nearly half a million inhabitants.

In our study we included cooperant children aged between 2 and 18 years. They belong to a group of low severity pediatric emergencies (white, blue or green in Romanian national triage codes) (11). Major emergencies, with a yellow or red triage code, were excluded, because BP values could have been affected. Uncompliant and agitated children and those with multiple injuries or burns were excluded too. For each participant of this study, a written parental consent was obtained.

Data collected by us included age, sex, weight, height and BP value.

The Centers Disease Control (CDC) recommended calculator (https://www.cdc.gov/healthyweight/bmi/calculator.html) for children and adolescents was used to correctly determine the BMI. Children with a BMI value lower than the $5^{\text {th }}$ percentile were considered underweight, those between the $5^{\text {th }}$ and $85^{\text {th }}$ percentiles were considered normal weight, overweight children had BMI values above the $85^{\text {th }}$ but below the $95^{\text {th }}$ percentile, and obesity was defined as BMI values greater than or at least equal to the $95^{\text {th }}$ percentile (12).

Blood pressure measurement was performed using Edan iM60 electronic devices (Edan, USA). During the BP measurement procedure, the child was at rest, in a comfortable sitting position. Cuffs corresponding to the size of the children's arm were used. Per protocol, an optimal width covered at least $40 \%$ of the circumference and optimal length was at least $80 \%$, up to $100 \%$ of the circumference of the arm (13).

The analysis of blood pressure values was made using the European Guide of the Hypertension Society, based on the percentiles for BP values by sex, age and height (14).

Statistical analysis was performed using IBM SPSS Statistics for Windows, version 25 (IBM Corp., Armonk, NY, USA). The level of statistical significance was set at $p<0.05$.

\section{RESULTS}

total of 335 children were included in the study, with a median age of the study group of 6.9 years (IQR: 4.2-9.8): 111 preschoolers (2-5 years), 171 schoolchildren (5-12 years) and 53 adolescents (12-18 years) (Table 1$)$. The distribution by sex was balanced, with a slight predominance of males (56.4\%). Regarding the type of emergency, most of the children (252, $75.2 \%)$ presented with non-emergency pathologies [white (25 children), and blue (227 children), triage code], whereas $24.8 \%$ (83) presented for minor emergencies (green triage 
code). Most patients were normal-weight $(n=204,60.9 \%)$, and $87(26.0 \%)$ children had elevated BMI values, being overweight $(n=25)$ or obese $(n=62)$ (Table 1). A percentage of $29.3 \%(n=98)$ of children had BP values above the $95^{\text {th }}$ percentile. The presence of high blood pressure values or obesity were not statistically correlated with the patient's gender (Table 2).

High blood pressure values measurements were not statistically corelated with the patient's age $(p=0.248, U=1$ 0682.0), while obese or overweight children had a median age of older than normal or underweight: 7.8 years (IQR: 5.3-10.2) vs. 6.5 years (IQR: 3.8-9.7), $\mathrm{p}=0.048, \mathrm{U}=9$ 252.5, $\mathrm{r}=0.1$.

Among overweight or obese children, $49.4 \%(n=47)$ had higher than normal values of blood pressure. This was statistically associated with a 3.4-fold higher risk of children with increased $\mathrm{BMI}$ of having high blood pressure values, $\quad \mathrm{p}<0.001, \quad \chi^{2}=23.10, \quad \mathrm{OR}=3.4$, $95 \%$ Cl 2.04-5.74.

\section{DISCUSSIONS}

This study presents a brief analysis of the prevalence of obesity in children over two years of age who presented for various acute conditions in the Emergency Department of "Alessandrescu-Rusescu" NIMCH, Bucharest, Romania.

We identified an increased prevalence of children with high BMI, a quarter of whom were overweight $(7.5 \%)$ or obese $(18.5 \%)$. These data are worrying, considering that a study started in 2010 and published in 2015, on 1108 children between 6-18 years old from Romania, identified an obesity rate of $10 \%$ (15). At the same time, this trend has been observed in almost every single European country, where the prevalence of overweight and obesity has considerably increased lately, with one in three children having a BMI above the normal limit $(16,17)$. The prevalence of obesity identified by us is equal to that reported for the United States (18.5\%), which corresponds to over 13.7 million obese children and adolescents in this country (18). However, in our study the prevalence of obesity in the age group 5-12 years was much higher than in adolescents (22.8\% vs. $15.1 \%$ ) compared to the US, where the prevalence of obesity was higher in adolescents (18.4\% vs. $20.6 \%)$ (18).

Particular attention should be paid to the high rate of overweight and obese children under five years of age. While a percentage of $8 \%$ of children

TABLE 1. Characteristics of patients by age categories

\begin{tabular}{lllll}
\hline & $\begin{array}{l}\text { Preschoolers } \\
(\mathbf{2 - 5} \text { years old) } \\
\mathbf{n = 1 1 1}\end{array}$ & $\begin{array}{l}\text { School children } \\
\mathbf{( 5 - 1 2} \text { years old) } \\
\mathbf{n = 1 7 1}\end{array}$ & $\begin{array}{l}\text { Adolescents } \\
(\mathbf{1 2 - 1 8} \text { years old), } \\
\mathbf{n = 5 3}\end{array}$ & Total \\
\hline Gender & & & & \\
\multicolumn{1}{c}{ Male } & $68(61.3 \%)$ & $93(54.4 \%)$ & $28(52.8 \%)$ & $189(56.4 \%)$ \\
\multicolumn{1}{c}{ Female } & $43(38.7 \%)$ & $78(45.6 \%)$ & $25(47.2 \%)$ & $146(43.6 \%)$ \\
\hline Underweight & $19(17.1 \%)$ & $19(11.1 \%)$ & $6(11.3 \%)$ & $44(13.1 \%)$ \\
Normal weight & $69(62.2 \%)$ & $101(59.1 \%)$ & $34(64.2 \%)$ & $204(60.9 \%)$ \\
Overweight & $8(7.2 \%)$ & $12(7.0 \%)$ & $5(9.4 \%)$ & $25(7.5 \%)$ \\
Obesity & $15(13.5)$ & $39(22.8 \%)$ & $8(15.1 \%)$ & $62(18.5 \%)$ \\
\hline HBP* & $37(33.3 \%)$ & $50(29.2 \%)$ & $11(20.8 \%)$ & $98(29.3 \%)$ \\
\hline
\end{tabular}

TABLE 2. Characteristics of patients by gender

\begin{tabular}{llll}
\hline & Female, $\mathbf{n = 8 8}$ & Male, $\mathbf{n = 9 7}$ & Statistical analysis \\
\hline Overweight & $40(46.0 \%)$ & $47(54.0 \%)$ & $\mathrm{p}=0.601, \chi^{2}=0.27, \mathrm{OR}=0.88$, \\
Obesity, $\mathrm{n}=87$ & & $95 \%$ CI $0.54-1.43$ \\
\hline $\mathrm{HBP}^{*}, \mathrm{n}=98$ & $48(49.0 \%)$ & $50(51.0 \%)$ & $\mathrm{p}=0.200, \chi^{2}=1.64, \mathrm{OR}=0.73$, \\
& & $95 \% \mathrm{CI} 0.46-1.18$ \\
\hline
\end{tabular}


under five years obese or overweight (19) was reported in Romania in 2002, we identified an increase of $20.7 \%$. Our results were comparable to those from European studies, which identified rates of up to $28.6 \%$ in this age group (under five) (20).

Depending on gender, the share of overweight or obese boys was higher, but without a significant difference compared to girls. This trend has been observed in most studies of childhood and adolescent obesity $(15,16)$.

Childhood obesity has become a real public health issue, because the effects of excess weight have an important impact on the individual from the beginning of life. Thus, in many studies, childhood obesity has been associated with cardiovascular disease, increased insulin resistance and type 2 diabetes, dyslipidemia, hepatic steatosis, sleep apnea syndrome, orthopedic problems, but especially social and psychological problems, school isolation, low self-esteem and even suicide, especially among older schoolchildren and adolescents $(16,21)$.

Most children maintain excess weight in adulthood, increasing the rate of morbidity and complications due to obesity (9). Although there are a number of factors that predispose to obesity since childhood, diet and lack of physical activity seem to play a key role (22). Early interventions to control childhood obesity are often difficult to do, because most parents do not recognize the problem until it worsens significantly. A whole series of parental perceptions that reflect a very high tolerance for overweight is summed up in the Romanian popular expression "fat and beautiful". Romanian doctors are not prepared to have a high rate of suspicion for the early diagnosis of overweight, nor do they have the support of health systems to provide the necessary care for an obese child. Under these conditions, social media can play an important role in raising awareness of the impact that overweight has on children's health. For example, in our country, in a large group dedicated to parents, Spitalul Virtual pentru Copii $(\mathrm{SVC}){ }^{\circledR}$, through the information published in a simple and explicit way, an attempt is made to raise awareness about children's health problems. The impact of the information presented in the SVC has been quantified several times as positive among parents $(23,24)$. A recent overweight post in SVC had over 70,000 views and over 600 comments and reactions (25). There- fore, social media can be considered as an effective tool of approaching the increase of overweight. Such a strategy is simple, inexpensive and sustainable. It requires only the active involvement of doctors, health system representatives and communication experts.

Obesity is a determining factor in the occurrence of hypertension in children. We measured the BP of the children included in the study, and $29.3 \%$ of them presented elevated values. This rate is higher than the average value from studies in other countries $(3,26)$. This aspect could have a bias coefficient due to BP measurement in patients who presented to hospital with acute illness. In a recent meta-analysis, Hanevold showed that about half of children presented white coat hypertension when the measurement took place in a medical environment (27). However, taking into account the previous statement, the HBP rate in our study group remains alarming. At the same time, the low prevalence of hypertension in children in other studies may also be due to the fact that measuring BP in children is not a routine in Emergency Departments (3).

In our study, we showed that overweight or obese children had a 3.4 higher risk of associating an elevated BP value. This observation has been highlighted since the early 2000s, when Must and colleagues showed that 25\% of obese children aged 5 to 11 years had HBP (28). The Bogalusa study revealed that overweight adolescents were eight times more likely than thin adolescents to associate with HBP that persists into adulthood (29). This observation has led to further studies showing that obese adults who were overweight or obese in childhood had an even higher risk of HBP than obese adults who had a normal weight as children. This may suggest that childhood adiposity has a lasting effect on the risk of HBP, even after normalizing BMI (30).

The small group of patients included in current study, the conditions of potential discomfort induced by the hospital environment in the Emergency Department, but also by mild acute illness, as well as the lack of dynamic measurements of $\mathrm{BP}$ values, represent some of the limitations of our study.

\section{CONCLUSIONS}

n our study we identified an increased prevalence of obesity in children and adolescents, 
comparable to the situation in other European countries. Moreover, we noticed a trend of these children to present higher blood pressure values. The proportion of obesity registered a tendency to double in the last decade in Romania. As the effects of these pathologies are not limited to childhood and continue to increase the risk of complications in adulthood, urgent action is needed on the part of healthcare professionals, parents and other members of society (communication experts, local authorities, teachers, etc.) to promote a healthy lifestyle. Parental and physician's awareness could be increased via social media tools.

Conflicts of interest: none declared. Financial support: none declared. Authors' contributions: All authors have contributed equally. All authors read and approved the final version of the manuscript.
1. Weaver DJ, Jr. Hypertension in Children and Adolescents. Pediatr Rev 2017;38:369-382.

2. Brady TM. Obesity-Related Hypertension in Children. Front Pediatr 2017:5:197.

3. Song P, Zhang Y, Yu J, et al. Global Prevalence of Hypertension in Children: A Systematic Review and Meta-analysis. JAMA Pediatr 2019:1-10.

4. Wuhl E. Hypertension in childhood obesity. Acta Paediatr. 2019;108(1):37-43.

5. Karki A, Shrestha A, Subedi N. Prevalence and associated factors of childhood overweight/obesity among primary school children in urban Nepal. BMC Public Health 2019;19:1055.

6. Andrade de Medeiros Moreira R, Ricardo Moreira T, Dias da Costa G, et al. Multilevel analysis of factors that influence overweight in children: research in schools enrolled in northern Brazil School Health Program. BMC Pediatr 2020;20:188.

7. Wilding $S$, Ziauddeen $N$, Smith $D$, et al. Are environmental area characteristics at birth associated with overweight and obesity in school-aged children? Findings from the SLOPE (Studying Lifecourse Obesity PrEdictors) population-based cohort in the south of England. BMC Med 2020;18:43.

8. Gaba A, Pedisic Z, Stefelova N, et al. Sedentary behavior patterns and adiposity in children: a study based on compositional data analysis. BMC Pediatr 2020;20:147.

9. Serdula MK, Ivery D, Coates RJ, et al. Do obese children become obese adults? A review of the literature. Preventive Medicine 1993;22:167-177.

10. Raitakari OT, Juonala M, Kahonen M, et al. Cardiovascular risk factors in childhood and carotid artery intima-media thickness in adulthood: the Cardiovascular Risk in Young Finns Study. JAMA 2003;290:2277-2283.

11. Ministry of Health. Protocol National din 25 martie 2019 de triaj al pacienților din structurile de primiri urgențe [Available from:
http://legislatie.just.ro/Public/ DetaliiDocument/212311.

12. Centers for Disease Control and Prevention. BMI Percentile Calculator for Child and Teen [2 March 2020]. Available from: https://www.cdc.gov/healthyweight/bmi/ calculator.html.

13. Clark JA, Lieh-Lai MW, Sarnaik A, Mattoo TK. Discrepancies between direct and indirect blood pressure measurements using various recommendations for arm cuff selection. Pediatrics 2002;110:920-923.

14. Lurbe E, Agabiti-Rosei E, Cruickshank JK, et al. 2016 European Society of Hypertension guidelines for the management of high blood pressure in children and adolescents. Journal of Hypertension 2016;34:1887-1920.

15. Barbu CG, Teleman MD, Albu AI, et al. Obesity and eating behaviors in school children and adolescents -data from a cross sectional study from Bucharest, Romania. BMC Public Health 2015;15:206.

16. Nittari G, Scuri S, Petrelli F, et al. Fighting obesity in children from European World Health Organization member states. Epidemiological data, medical-social aspects, and prevention programs. Clin Ter 2019;170:e223-e230.

17. Yusuf ZI, Dongarwar D, Yusuf RA, et al. Social Determinants of Overweight and Obesity Among Children in the United States.

Int J MCH AIDS 2020;9:22-33.

18. Centers for Disease Control and Prevention. Childhood Obesity Facts. Prevalence of Childhood Obesity in the United States [Available from: https://www.cdc.gov/obesity/data/ childhood.html.

19. Nanu M. Nutritional Status of Children under 5 Years Old. National Nutritional Surveillance Programme 1993-2002. Alfred Rusescu Institute for Mother and Child Care: Bucharest. Romania, 2003.

20. Jones RE, Jewell J, Saksena R, et al. Overweight and Obesity in Children under 5 Years: Surveillance Opportunities and Challenges for the WHO European Region.
Front Public Health 2017;5:58.

21. Kotchen TA. Obesity-related hypertension: epidemiology, pathophysiology, and clinical management.

Am J Hypertens 2010;23:1170-1178.

22. Misra A, Khurana L. Obesity and the metabolic syndrome in developing countries. J Clin Endocrinol Metab 2008;93(11 Suppl 1):S9-S30.

23. Craiu M, Stan I, Comanici V. Role of Social Media in exploring parental expectations regarding usage and providing education on nebulized medication in children. European Respiratory Journal 2019;54 (Suppl 63):OA5342.

24. World Health Organization - Europe. Dr Mihai Craiu, paediatrician, Bucharest, Romania [Available from: http://www. euro.who.int/en/health-topics/diseaseprevention/vaccines-and-immunization/ vaccine-heroes/dr-mihai-craiu,paediatrician,-bucharest,-romania.

25. Mihai Craiu. Cresterea în greutate pe durata izolării din timpul pandemiei COVID-19, Spitalul Virtual pentru Copii 2020 [Available from:

https://www.facebook.com/drCraiuMihai/ posts/1127469127645787.

26. Genovesi S, Giussani M, Pieruzzi F, et al. Results of blood pressure screening in a population of school-aged children in the province of Milan: role of overweight. Journal of Hypertension 2005;23:493-497.

27. Hanevold CDJH. White coat hypertension in children and adolescents 2019;73:24-30.

28. Must A, Strauss RS. Risks and consequen ces of childhood and adolescent obesity. Int J Obes Relat Metab Disord 1999;23 Suppl 2:S2-S11.

29. Srinivasan SR, Bao W, Wattigney WA, Berenson GS. Adolescent overweight is associated with adult overweight and related multiple cardiovascular risk factors: the Bogalusa Heart Study. Metabolism 1996;45:235-240.

30. Gunta S, Mak R. Hypertension in children with obesity. World J Hypertens 2014;4:15-24. 